\title{
Gas/oil IFT, three-phase relative permeability and performance of Water-Alternating-Gas (WAG) injections at laboratory scale
}

\author{
Jahanbakhsh A, Shahverdi H, Fatemi SM, Sohrabi M \\ Centre for Enhanced Oil Recovery and $\mathrm{CO}_{2}$ Solutions, Institute of Petroleum Engineering, Heriot-Watt University, Edinburgh, United Kingdom
}

Correspondence: Amir Jahanbakhsh, Research Centre for Carbon Solutions, Heriot-Watt University, Edinburgh, United Kingdom, Email A.Jahanbakhsh@hw.ac.uk

Received: January 05, 2018 | Published: January 29, 2018

Copyright@ 2018 Jahanbakhsh et al. This is an open access article distributed under the terms of the Creative Commons Attribution License, which permits unrestricted use, distribution, and reproduction in any medium, provided the original author and source are credited.

\begin{abstract}
Gas/oil interfacial tension (IFT) is one of the most important parameters that impact the performance of gas injection in an oil reservoir. The choice or design of the composition of the injection gas for improving the oil recovery is usually affected by the gas/oil IFT. In conventional reservoir simulation, IFT does not explicitly appear in the equations of flow and therefore its effect must be captured by the shape and values of relative permeability of existing phases. A few studies have been previously reported for IFT effects on two-phase flow but very little have been done to investigate gas/oil IFT effect under three-phase flow conditions. Previously, we performed series of core-flood experiments at Heriot-Watt University to investigate the effect of changing gas/oil IFT value (immiscible and nearmiscible) on WAG injections. In this paper, we review published laboratory studies on the impact of gas/oil IFT variation on three-phase relative permeability, performance of WAG injections, and in particular reduction of remaining oil saturation. The review shows that in three-phase systems, as IFT varies between gas and oil, the relative permeabilities of all the three phases (gas, oil and water) will be affected. The remaining oil saturation keeps decreasing during WAG injections at very low IFT (near-miscible) conditions and performance of near-miscible WAG is generally better than that of immiscible WAG.
\end{abstract}

\section{Part I: Effect of gas/oil IFT on three-phase relative permeability}

Although the effect of IFT on two-phase relative permeability has been extensively investigated but there are only very few research studies on the effect of IFT on three-phase relative permeabilities. Research results at two-phase conditions showed that the IFT reduction increases the relative permeability of both phases but not necessarily equally. Generally, it has been observed that as the system moves from immiscible toward miscible conditions, simultaneous flow of gas and oil in the same pore improves and as a result, the relative permeability increases and its curvature reduces. ${ }^{1-8}$ The following paragraphs summarize the results of available research results for effect of IFT variation on three-phase relative permeability.

Delshad et al. ${ }^{9}$ measured steady-state, two- and three-phase relative permeability for low IFT mixture of brine/oil/surfactant/alcohol in Berea sandstone cores at constant capillary number of $10^{-2}$. They concluded that in three-phase flow at low IFT conditions, the relative permeability of each phase was a function of its own saturation.

Dria et al. ${ }^{10}$ reported steady-state three phase $\mathrm{CO}_{2} /$ oil/brine relative permeabilities in a water-wet grainstone dolomite core. They injected fluids at $71^{\circ} \mathrm{C}$ and $1400 \mathrm{psia}(9.65 \mathrm{MPa})$, to be representative of reservoir conditions. Their results also show that the relative permeability of each phase depends only on the saturation of that phase. is while the previous three-phase relative permeability measurements that had been performed with low pressure $\mathrm{N}_{2}$ gas or air showed that the relative permeability of each phase depended on two saturations. Therefore, they concluded that three-phase relative permeability behaves differently at low IFT $\left(\mathrm{CO}_{2} /\right.$ oil $)$ and high IFT $\left(\mathrm{N}_{2} /\right.$ oil) conditions.

Cinar \& Orr ${ }^{11}$ investigated the effect of IFT reduction on three-phase relative permeabilities for water-wet wettability condition using three-phase analogous liquid systems. The IFT between two of the phases could be varied in the analogous liquid systems while the IFTs between the other pairs of phases can be held roughly constant. They concluded that the water (wetting phase) relative permeability was not affected by IFT reduction but the relative permeability to oil (intermediate phase) and gas (non-wetting phase) were affected considerably.

Cinar et al. ${ }^{12}$ reported three-phase relative permeability measurements that included the combined effects of IFT variation and wettability. Similar to their previous study, they used an analogous liquid system for investigation of the effect of IFT variations at atmospheric pressure. Their results showed that, in water-wet system, as gas/oil IFT decreased, relative permeabilities of these two phases increased but water relative permeability remained almost unaffected by IFT at any water saturation. However, in oil-wet system, water relative permeability $\left(\mathrm{k}_{\mathrm{rw}}\right)$ decreased with decrease of gas/oil IFT only at low values of water saturation.
Submit your Article | www.ologypress.com/submit-article

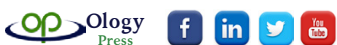

Citation: Jahanbakhsh A, Shahverdi H, Fatemi SM, et al. Gas/oil IFT, Three-phase relative permeability and performance of Water-Alternating-Gas (WAG) injections at laboratory scale. J Oil Gas Petrochem Sci. (20I8); I (I): I0-I6. DOI: I0.3088I/jogps.00005 
Fatemi et al. ${ }^{13,14}$ performed series of WAG experiments on $65 \mathrm{mD}$ mixed-wet Clashach sandstone core at three different gas/oil IFT values of $0.04,0.15$ and $2.7 \mathrm{mN} \cdot \mathrm{m}^{-1}$. They used a synthetic brine as the water phase and a binary mixture of methane and n-butane for gas and oil phases. Jahanbakhsh et al. ${ }^{15}$ estimated three-phase relative permeabilities from the tertiary gas injection period of WAG injections for three different IFT values. The gas/oil IFT reduction affects the relative permeability of all three phases. They concluded that as the gas/oil IFT decreases, oi relative permeability $\left(\mathrm{k}_{\mathrm{ro}}\right)$ and gas relative permeability $\left(\mathrm{k}_{\mathrm{rg}}\right)$ increase but the behavior of $\mathrm{k}_{\mathrm{rw}}$ is uncertain. Moreover, the IFT reduction was more effective at very low IFT $(0.04$ $\mathrm{mN} / \mathrm{m}$ ) conditions, with minor effects at intermediate values.

To summarize, according to the few available literature for three-phase systems, generally as IFT between one pair of phases, e.g. oil and gas changes, the relative permeabilities of all the three phases (gas, oil and water) will be affected. It has been observed that by reduction of gas/ oil IFT, $\mathrm{k}_{\mathrm{ro}}$ and $\mathrm{k}_{\mathrm{rg}}$ increase but no firm conclusion can be made for $\mathrm{k}_{\mathrm{rw}}$. The degree of changes in relative permeability of each phase and its dependency on its own saturation and other fluid saturations should be further investigated at low IFT conditions. ${ }^{9-12,15}$

\section{Part 2: Performance of immiscible and miscible water-alternating-gas injections}

Water-Alternating-Gas (WAG) injection is a proven EOR technique to unlock some of the remaining oil and has been applied in several fields since 1950. The WAG injection can be miscible (MWAG) or immiscible (IWAG). Process. However, some authors believe that MWAG in reservoir scale is a near-miscible process. ${ }^{16}$ Performance of WAG injections at field scale has been reported between $5 \%$ to $10 \%$ OOIP. ${ }^{17,18}$ Although it is expected that WAG injections improve both macroscopic sweep and microscopic displacement efficiencies, still we need to investigate governing mechanisms, improve the performance and optimize WAG parameters. This section reviews published researches investigating performance of immiscible, and miscible and near-miscible WAG processes.
Skauge \& Larsen ${ }^{19}$ conducted several immiscible WAG coreflood experiments on sandstone cores of outcrop Berea and North Sea reservoir rocks under different wettability conditions of waterwet, oil-wet and intermediate-wet. In their tests gas injection was performed on horizontal cores for Berea, silanized Berea and North Sea reservoirl core (R1) at constant differential pressure but for the North Sea reservoir cores 2, 3 and 4 (R2, R3 and R4) the gas injection was in a gravity stable vertical displacement. For the reservoir cores, experiments were performed in the range of $100^{\circ} \mathrm{C}$ and 300 bars, and the fluids were recombined reservoir oil and gas. For outcrop cores, synthetic fluids (mixtures of methane and decane) were used and experiments were performed at a selected value of pressure but ambient temperature. The permeabilities of the tested cores were as follows: R1:100-200 mD, R2: 30-300 mD, R3: 800-2000 mD and R4: $300-800 \mathrm{mD}$. Their results showed that the remaining oil saturation could be significantly reduced by three-phase flow (immiscible) compared to two-phase waterflood or only gas injection, from initial conditions. Table 1 and Table 2 present the oil saturations and oil recovery, respectively, for different experiments including WAGDI (started with gas injection(drainage) followed by water injection (imbibition)) and WAG-ID (starting with water injection (imbibition) followed by gas injection (drainage)) injection scenarios. Figure 1 compares the changes in oil saturation for Berea and R1 cores during immiscible WAG-ID and DI injections. The oil saturations for two complete cycles of alternative gas and water injection were available only for these two cores. It was observed that for both set of cores, Berea and North Sea, when the WAG processes started with gas injection it had higher oil recovery than those tests, which started with water flooding. Furthermore, in these immiscible WAG processes, the largest portion of recovery (decrease in oil saturation) occurred in the first cycle of injections and the decrease in oil saturation was not significant in the later injection periods. In addition, comparing the results obtained from the North Sea reservoir cores, it could be concluded that the performance of WAG in mixed-wet system was much better than water-wet system whether it started with gas injection or water flooding.

Table I Oil saturation for WAG experiments by Skauge \& Larsen ${ }^{19}$

\begin{tabular}{lllllllllll}
\hline \multirow{2}{*}{ Rock } & \multirow{2}{*}{ Orientation } & \multirow{2}{*}{ Wettability } & \multicolumn{3}{c}{ WAG-DI (starts with Gas) } & \multicolumn{4}{c}{ WAG-ID (starts with Water) } \\
& & & $\mathbf{S}_{\text {oi }}$ & $\mathbf{S}_{\text {or }} \mathbf{G I}$ & $\mathbf{S}_{\text {or }}$ WI & $\mathbf{S}_{\text {or }}$ G2 & $\mathbf{S}_{\text {oi }}$ & $\mathbf{S}_{\text {or }}$ & $\mathbf{S}_{\text {or }}$ G I & $\mathbf{S}_{\text {or }}$ \\
Werea (B) & Horizontal & WW & 0.733 & 0.213 & 0.079 & 0.075 & 0.73 & 0.44 & 0.438 & 0.391 \\
Silanized Berea* & Horizontal & NA & 0.725 & 0.236 & 0.158 & 0.156 & 0.699 & 0.147 & 0.141 & 0.089 \\
RI(North Sea) & Horizontal & WW & 0.692 & 0.23 & 0.201 & 0.191 & 0.778 & 0.377 & 0.359 & 0.303 \\
R2(North Sea) & Vertical & MW & 0.64 & 0.35 & 0.16 & - & 0.63 & 0.28 & 0.18 & - \\
R3(North Sea) & Vertical & MW & 0.775 & 0.093 & - & - & - & - & - & - \\
R4(North Sea) & Vertical & WW & 0.381 & 0.191 & 0.145 & - & 0.489 & 0.218 & - & - \\
\hline
\end{tabular}

*Wettability was initially altered to oil-wet by silanization but it changed from oil-wet to water-wet after series of experiments

Table 2 Oil recovery (\%) for WAG experiments by Skauge \& Larsen ${ }^{19}$

\begin{tabular}{lllll}
\hline Rock & Orientation & Wettability & Secondary WAG & Tertiary WAG \\
\hline Berea (B) & Horizontal & WW & 89.7 & 46.4 \\
Silanized Berea & Horizontal & NA & 78.5 & 87.2 \\
RI & Horizontal & WW & 72.4 & 61.1
\end{tabular}


(Table 2 continue...)

\begin{tabular}{lllll} 
R2 & Vertical & MW & 75 & 71.4 \\
R3 & Vertical & MW & 88 & - \\
R4 & Vertical & WW & 61.9 & 55.4 \\
\hline
\end{tabular}

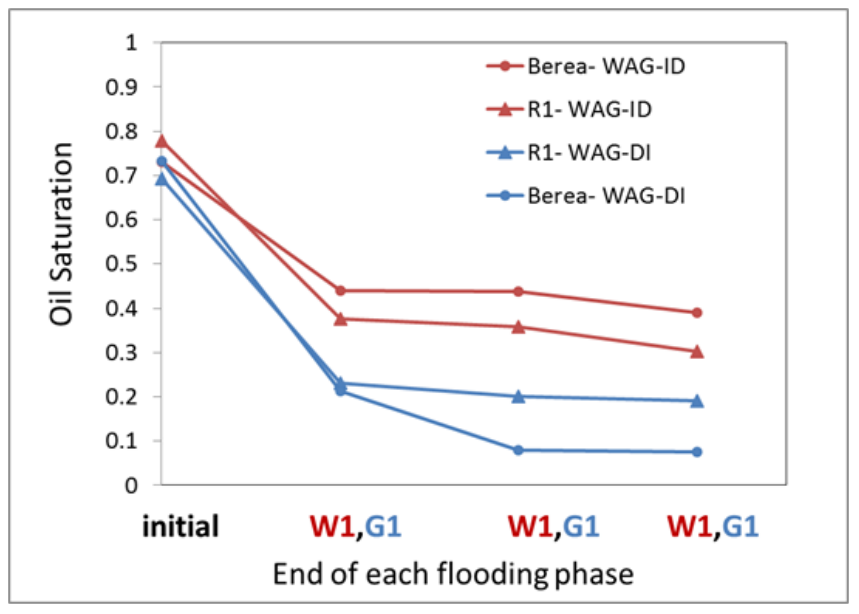

Figure I Oil saturation at the end of each flooding phase during WAG-DI (Blue) and WAG-ID (Red) for Berea Sandstone and RI North Sea cores Skauge \& Larsen. ${ }^{19}$

Minssieux \& Duquerroix ${ }^{20}$ performed immiscible WAG experiments on an $80 \mathrm{~cm}$ composite sandstone core. The WAG experiments were performed after secondary water flooding and started with gas injection. The core was water-wet with permeability and porosity of $130 \mathrm{mD}$ and 0.11 , respectively. The experiments were conducted at $80^{\circ} \mathrm{C}$ with constant injection rates and the core was horizontally oriented. Table 3 summarizes the results of their WAG experiments. They concluded that when oil was under-saturated, oil swelling in presence of injected methane combined with gas trapping during imbibition helped to mobilize oil during the WAG injection. They also concluded that in the absence of oil swelling, three-phase hysteresis involved in WAG injection, led to some extra but limited and slow oil production. Additionally, the oil saturation could be significantly reduced by three-phase flow compared to two-phase water flood.
Table 3 Results of Immiscible WAG experiments in water-wet sandstone core $^{20}$

\begin{tabular}{lllll}
\hline Experiment & Swelling & $\mathbf{S}_{\text {oi }}$ & $\mathbf{S}_{\text {or }} \mathbf{W 1}$ & $\mathbf{S}_{\text {or }}$ WAG \\
\hline WAG-ID & $5 \%$ vol. & 0.95 & 0.44 & 0.317 \\
WAG-ID & $13 \%$ vol. & 0.56 & 0.325 & 0.152 \\
WAG-ID & no Swelling & 0.91 & 0.44 & 0.303 \\
SWAG & no Swelling & 0.78 & 0.467 & 0.387 \\
\hline
\end{tabular}

Egermann et al. ${ }^{21}$ reported the results of a series of four cyclic gas and water injection experiments on a water-wet limestone core $(\varphi=0.23$, $\mathrm{k}=215 \mathrm{mD}$ ) with different initial saturations. In each Series (S) there are two cycles and each cycle includes drainage (gas injection) and imbibition (water flooding) experiments. The drainage and imbibition experiments were at constant pressure and constant injection rate, respectively. The experiments were performed at ambient condition and the core was horizontally oriented. The fluids used in these experiments were soltrol 70 , brine $(30 \mathrm{~g} / \mathrm{l} \mathrm{NaCl})$ and nitrogen. The gas injections were immiscible or at high IFT conditions (IFT oil/gas $=27$ $\left.\mathrm{mNm}^{-1}\right)$. Table 4 and Table 5 summarize the changes in oil saturation after cyclic gas and water injections in all series. For S1, the core was initially saturated with water but displaced by oil injection until no further water was produced (to establish irreducible water saturation $\mathrm{S}_{\mathrm{wi}}$ ). The cyclic gas and water injection was then performed, which is equivalent to WAG-DI injection. In S2, the cyclic injections started after secondary water flooding where oil had reached to its value. For S3 and S4 by steady-state injection of oil and water, an intermediate value for oil saturation was established before starting the cyclic injections. These experiments are equivalent to WAG-ID injection. The oil saturation can be considerably lower by three-phase flow compared to two-phase water flooding or gas injection. The majority of the oil recovery took place during the first three injections and no substantial production was obtained after the subsequent injections.

Table 4 Oil saturation during Series I (WAG-DI)21

\begin{tabular}{llllll}
\hline Experiment & $\mathbf{S}_{\text {oi }}$ & $\mathbf{S}_{\text {or }} \mathbf{G 1}$ & $\mathbf{S}_{\text {or }} \mathbf{W} 1$ & $\mathbf{S}_{\text {or }} \mathbf{G} 2$ & $\mathbf{S}_{\text {or }}$ W2 \\
\hline $\mathrm{S} 1\left(\mathrm{~S}_{\mathrm{oi}}=0.51, \mathrm{~S}_{\mathrm{wir}}=0.49\right)$ & 0.51 & 0.28 & 0.21 & 0.19 & 0.19 \\
\hline
\end{tabular}

Table 5 Oil saturation during Series 2, 3, 4 (WAG-ID)21

\begin{tabular}{llllll}
\hline Experiment & $\begin{array}{l}\mathbf{S}_{\text {or }} \mathbf{W} \mathbf{1} \\
\text { (initial) }\end{array}$ & $\mathbf{S}_{\text {or }} \mathbf{G} \mathbf{1}$ & $\mathbf{S}_{\text {or }} \mathbf{W} 2$ & $\mathbf{S}_{\text {or }} \mathbf{G}$ 3 & $\mathbf{S}_{\text {or }} \mathbf{W} 3$ \\
\hline $\mathrm{S} 2\left(\mathrm{~S}_{\mathrm{ori}}=0.31, \mathrm{~S}_{\mathrm{wi}}=0.69\right)$ & 0.31 & 0.24 & 0.18 & 0.18 & 0.18 \\
$\mathrm{~S} 3\left(\mathrm{~S}_{\mathrm{oi}}=0.39, \mathrm{~S}_{\mathrm{wi}}=0.61\right)$ & 0.39 & 0.25 & 0.19 & 0.18 & 0.18 \\
$\mathrm{~S} 4\left(\mathrm{~S}_{\mathrm{oi}}=0.42, \mathrm{~S}_{\mathrm{wi}}=0.58\right)$ & 0.42 & 0.27 & 0.22 & 0.20 & 0.19 \\
\hline
\end{tabular}


Element et al. ${ }^{22}$ pursued a laboratory study on immiscible WAG-ID and DI floods in water-wet and mixed-wet (intermediate-wet) Berea sandstone cores. Water-wet and mixed-wet cores had the same porosity of 0.19 but gas permeability of 328 and $393 \mathrm{mD}$, respectively. Decane, distilled water and nitrogen were the fluids used in their displacement experiments. The development of mixed wettability was done by aging the core with stock tank oil. The injections were performed vertically from top of the core. The flooding sequences under the both wettability conditions started with water flooding for WAG-ID experiment and with gas for WAG-DI experiment. A higher recovery was achieved for water-wet and mixed-wet cores for WAG-DI (gas injection before first waterflood). The same conclusion has been made from research results of Skauge and Larsen ${ }^{19}$ and ours. Table 6 presents the oil saturation obtained after each drainage and imbibition process in a WAG-ID injection for the water-wet core. These data were the only published data in their paper. Figure 2 compares the results of tertiary WAG injection performed by Element et al. ${ }^{22}$ with WAG-ID and DI performed by Skauge and Larsen. ${ }^{19}$

Table 6 Oil saturation during immiscible WAG-ID injection for water-wet Berea sandstone core ${ }^{22}$

\begin{tabular}{|c|c|c|c|c|c|c|c|c|c|}
\hline Experiment & $\mathbf{S}_{\mathrm{oi}}$ & $\mathbf{S}_{\text {or }} \mathbf{W I}$ & $\mathbf{S}_{\text {or }} \mathbf{G I}$ & $\mathrm{S}_{\text {or }} \mathbf{W} 2$ & $\mathbf{S}_{\mathrm{or}} \mathbf{G} 2$ & $\mathbf{S}_{\text {or }}$ W3 & $\mathbf{S}_{\text {or }} \mathbf{G} 3$ & $S_{\text {or }}$ W4 & $\mathbf{S}_{\text {or }} \mathbf{G 4}$ \\
\hline WAG-ID & 0.74 & 0.46 & 0.31 & 0.26 & 0.25 & 0.24 & 0.23 & 0.22 & 0.21 \\
\hline
\end{tabular}

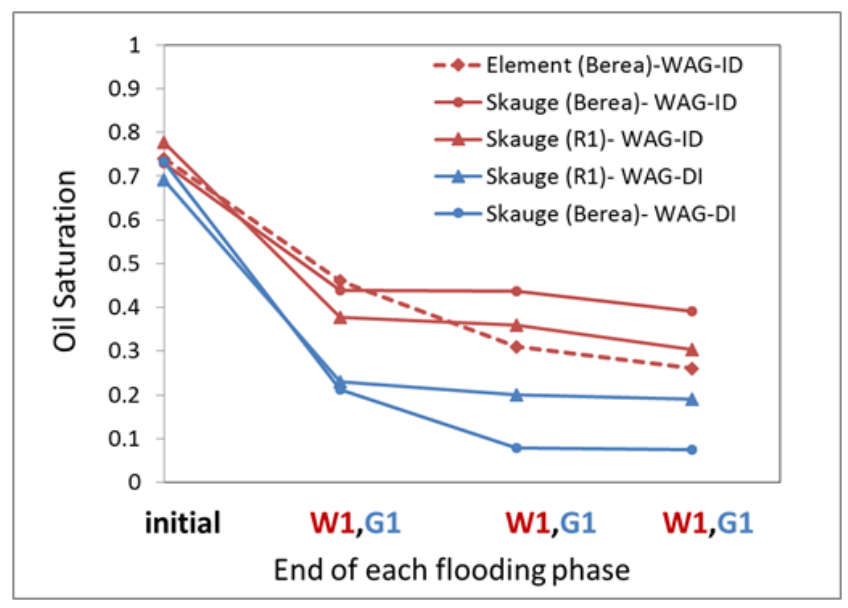

Figure 2 Oil saturation at the end of each flooding phase during WAG-DI (Blue) and WAG-ID (Red) WAG injections. ${ }^{19,22}$

Kulkarni \& $\mathrm{Rao}^{23}$ performed an experimental study to evaluate effect of miscibility and brine composition on performance of WAG injection. They compare ultimate recovery of WAG-ID and continues gas injections (CGI). They used a Berea sandstone core sample, pure $\mathrm{CO}_{2}$, n-Decane and two synthetic brines. Immiscible $\mathrm{CO}_{2}$ injections were conducted at $500 \mathrm{psi}$ and miscible injections at 2500 psi considering MMP of $1880 \mathrm{psi}$ for $\mathrm{CO}_{2} / \mathrm{n}$-Decane system. They defined a Tertiary Recovery Factor (TRF) to normalize the recoveries based on injected pore volume of $\mathrm{CO}_{2}$ and make the ultimate recoveries for all sceneries comparable. TRF is remaining oil after secondary water flooding divided by total volume of injected $\mathrm{CO}_{2}$ during the

tertiary recovery. Table 7 compares TRF for immiscible and miscible CGI and WAG injections. Based on TRF, WAG injections performed better than the CGI. Moreover, miscible CGI and WAG outperformed immiscible injection scenarios substantially. Finally, they suggested that a continuous gas injection followed by a WAG injection would optimize tertiary recovery.

Table 7 Tertiary recovery factors for miscible and immiscible CGI and WAG injections $^{23}$

\begin{tabular}{lll}
\hline Experiment & Miscibility & TRF \\
\hline CGI-Brinel & miscible & 1.054 \\
CGI-Brinel & immiscible & 0.112 \\
WAG-Brinel & miscible & 1.473 \\
WAG-Brinel & immiscible & 0.229 \\
CGI-Brine2 & miscible & 0.844 \\
CGI-Brine2 & immiscible & 0.218 \\
WAG-Brine2 & miscible & 0.611 \\
WAG-Brine2 & immiscible & 1.114 \\
\hline
\end{tabular}

At Heriot-Watt University (HWU), several WAG experiments at three gas/oil IFT values of 0.04 (near-miscible), 0.15 and $2.7 \mathrm{mNm}$ 1 (immiscible) have been performed. ${ }^{13,14,24}$ Table 8 summarizes different WAG experiments started with water (WAG-ID) with the oil saturation after cyclic injection of water and gas for different gas/ oil IFT values in 65 and $1000 \mathrm{mD}$ water-wet and mixed-wet Clashach sandstone cores. Table 9 presents WAG experiments started with gas (WAG-DI) and the oil saturation after cyclic injections for different gas/oil IFT values in $65 \mathrm{mD}$ mixed-wet core.

Table 8 Oil saturations during WAG-ID injection in 65 and 1000 mD Clashach cores ${ }^{13-14,24}$

\begin{tabular}{llllllllll}
\hline Rock & Wettability & IFTg/o & $\mathbf{S}_{\text {oi }}$ & $\mathbf{S}_{\text {or }} \mathbf{W} \mathbf{I}$ & $\mathbf{S}_{\text {or }} \mathbf{G I}$ & $\mathbf{S}_{\text {or }} \mathbf{W} 2$ & $\mathbf{S}_{\text {or }} \mathbf{G} 2$ & $\mathbf{S}_{\text {or }} \mathbf{W} 3$ & $\mathbf{S}_{\text {or }} \mathbf{G 3}$ \\
\hline $1000 \mathrm{mD}$ & $\mathrm{MW}$ & 0.04 & 0.92 & 0.23 & 0.115 & 0.06 & 0.009 & - & - \\
$65 \mathrm{mD}$ & $\mathrm{WW}$ & 0.04 & 0.82 & 0.415 & 0.30 & 0.26 & 0.2 & 0.167 & 0.095 \\
$65 \mathrm{mD}$ & $\mathrm{MW}$ & 0.04 & 0.82 & 0.18 & 0.144 & 0.127 & 0.105 & 0.096 & 0.027 \\
$65 \mathrm{mD}$ & $\mathrm{MW}$ & 0.15 & 0.82 & 0.271 & 0.265 & 0.247 & 0.234 & 0.224 & 0.214 \\
$65 \mathrm{mD}$ & $\mathrm{MW}$ & 2.7 & 0.82 & 0.18 & 0.305 & 0.29 & 0.29 & 0.28 & 0.28 \\
\hline
\end{tabular}


Table 9 Oil saturations during WAG-DI injection in $65 \mathrm{mD}$ Clashach core ${ }^{13-14}$

\begin{tabular}{|c|c|c|c|c|c|c|c|c|c|c|c|}
\hline Rock & Wettability & IFTg/o & $S_{o i}$ & $S_{\text {or }}$ G1 & $S_{\text {or }} \mathbf{W 1}$ & $S_{\text {or }} G 2$ & $\mathbf{S}_{\text {or }} \mathbf{W} 2$ & $S_{\text {or }}$ G3 & $S_{\text {or }} \mathbf{W} 3$ & $S_{\text {or }} G 4$ & $S_{\text {or }} W 4$ \\
\hline $65 \mathrm{mD}$ & MW & 0.04 & 0.82 & 0.29 & 0.19 & 0.16 & 0.14 & 0.11 & 0.095 & 0.07 & 0.05 \\
\hline $65 \mathrm{mD}$ & MW & 0.15 & 0.82 & 0.305 & 0.168 & 0.153 & 0.141 & 0.133 & 0.124 & 0.113 & 0.105 \\
\hline $65 \mathrm{mD}$ & MW & 2.7 & 0.82 & 0.35 & 0.089 & 0.082 & 0.068 & 0.064 & 0.06 & 0.06 & 0.057 \\
\hline
\end{tabular}

"G" and "W" denote the displacement processes of gas injection and water flooding respectively. The number behind the letter refers to the cycle number, i.e., G2 refers to gas injection in the second cycle. Figure 3 shows that the oil saturation in the $65 \mathrm{mD}$ mixed-wet core, at IFTg/o of 0.15 and $2.7 \mathrm{mNm}^{-1}$ conditions, decreased insignificantly after the secondary water flooding. This means during any of the subsequent cycles of WAG injection (i.e., end of G1, W2, G2, W3 and G3; the red curve) the oil saturation decreased due to three-phase flow mechanism and hysteresis effect but the reduction is limited while in the nearmiscible conditions (IFTg/o $=0.04 \mathrm{mNm}^{-1}$ ) it decreased continuously even during the later stages of WAG injection. The similar continuous trend of reduction in oil saturation during the near-miscible WAG injection can be seen in the experimental results of the $1000 \mathrm{mD}$ core. Unlike the WAG-ID results, WAG-DI at high gas/oil IFT value shows better performance than intermediate IFT value. Similarly, the WAG-DI at near-miscible conditions, had lower performance than WAG-DI at high IFT value, but continuous reduction of oil during the cyclic injections at near-miscible conditions caused even a better performance at the end of forth cycle. As a result, it can be concluded that in WAG-ID and DI injections at near-miscible conditions, the oil continuously decreased during the injections and the recovery was higher compared with the injections at intermediate and high gas/oil IFT values.

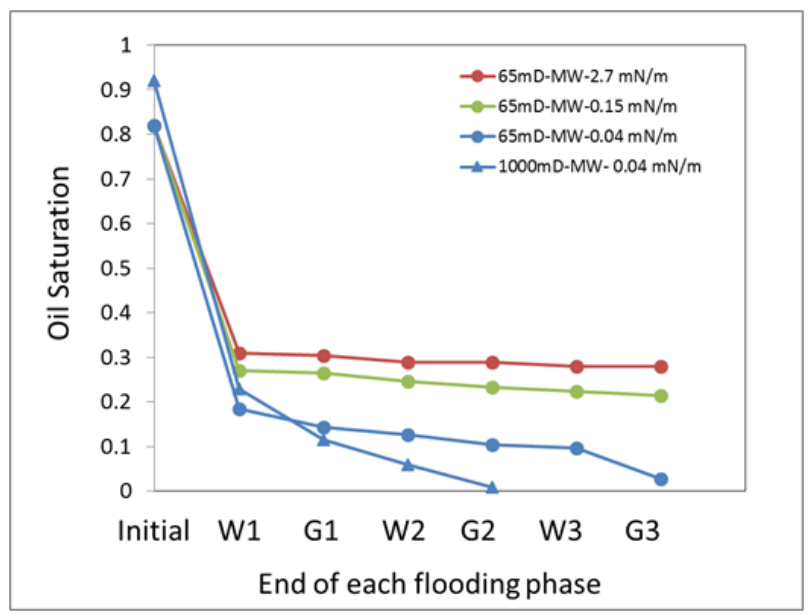

Figure 3 Oil saturation at the end of each flooding phase during WAG-ID injections in 65 and $1000 \mathrm{mD}$ mixed-wet cores. ${ }^{13-14,24}$

Comparing the results of WAG-ID and WAG-DI injections in 65 $\mathrm{mD}$ mixed-wet core at immiscible conditions $\left(0.15\right.$ and $\left.2.7 \mathrm{mNm}^{-1}\right)$ shows that the performance of WAG injection started with gas was better than the WAG started with water. However, the near-miscible
WAG-ID injection, especially in the first cycle, outperformed WAGDI injection. Moreover, similar to the results obtained by Skauge and Larsen ${ }^{19}$ the performance of WAG in mixed-wet system was much better than water-wet system for the $65 \mathrm{mD}$ core and still much better in the $1000 \mathrm{mD}$ mixed-wet core (as expected).

The sequence of injections in the study by Minssieux ${ }^{20}$ was similar to the most of experiments that have been conducted at HWU. The results of their study for WAG injection with zero and $5 \%$ oil swelling were compared to the immiscible and near-miscible experiment that we conducted on $65 \mathrm{mD}$ water-wet and mixed-wet cores (Figure 4). The results of both studies show that WAG injection at nearmiscible conditions or with high oil swelling has higher recovery than immiscible WAG.

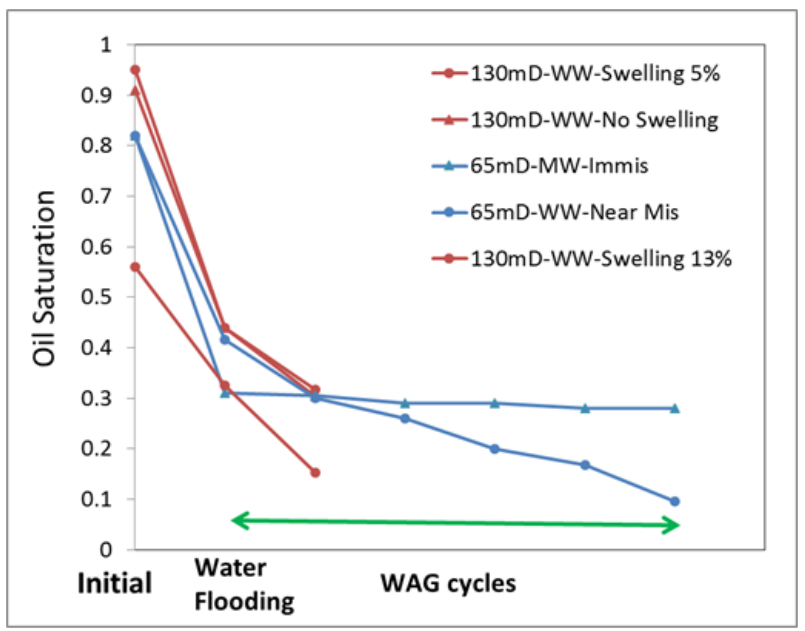

Figure 4 Comparison of Oil saturation at the end of each flooding phase during WAG-ID experiments performed by Minssieux (Red) and Fatemi et al. (Blue). ${ }^{13,14,20}$

The results of WAG-ID experiment by Element et al. ${ }^{22}$ was compared with two most similar experiments performed at HWU; WAG-ID injection into $65 \mathrm{mD}$ once with water-wet wettability at near-miscible conditions and once with mixed-wet wettability at immiscible conditions (Figure 5). The immiscible WAG injections for both studies showed very similar behavior and no significant oil production was obtained after the first WAG cycle. However, the oil saturation at near-miscible conditions decreased considerably after the first cycle. Considering the trend of changes in oil saturation during WAG injections, it is revealed that, as expected, the recovery of WAG at near-miscible conditions is significantly higher than under immiscible conditions. 
Kamali et al. ${ }^{25}$ performed series of continues $\mathrm{CO}_{2}$ injection at immiscible, near-miscible and miscible conditions to co-optimize $\mathrm{CO}_{2}$ EOR and Storage processes. They injected supercritical $\mathrm{CO}_{2}$ into an oil saturated sandstone core sample at three different pressures of 1300 , 1700 and $2100 \mathrm{psi}$ representative for IFT values of 2.78 (immiscible), 0.06 (near-miscible) and 0.0 (miscible) $\mathrm{mN} / \mathrm{m}$ respectively. The experiments were conducted on a Bentheimer sandstone core sample with $23.8 \%$ porosity and $1700 \mathrm{mD}$ permeability at temperature of $70^{\circ} \mathrm{C}$. Their results showed that ultimate recovery of near-miscible and miscible $\mathrm{CO}_{2}$ injections could reach up to $73 \%$ of original oil in place, which was $18 \%$ higher than that of immiscible displacement. Additionally, they found that miscible injection had higher recovery than near-miscible at early stage of injections (up to 1 pore volume) but then both became almost the same.

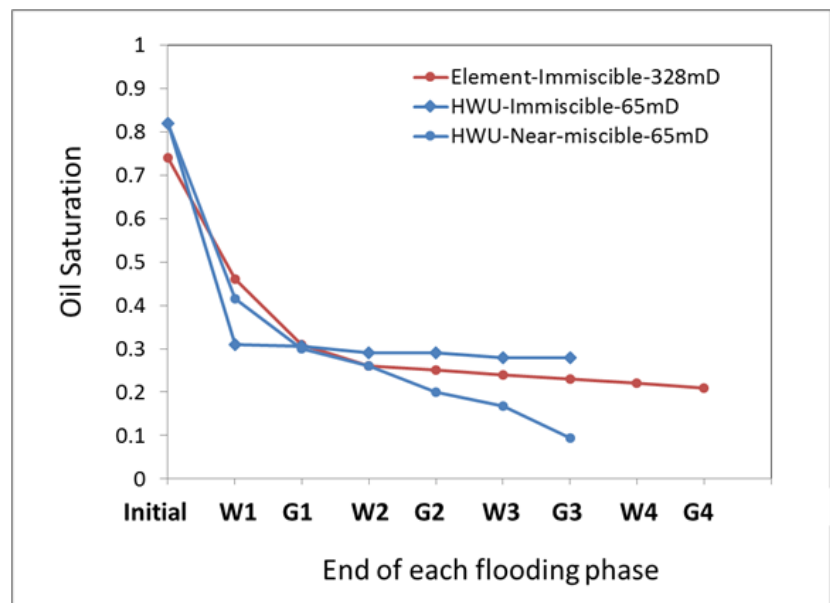

Figure 5 Oil saturation at the end of each flooding phase during WAG-ID injections by Element et al. (Red) and Fatemi et al. (Blue). ${ }^{13-14,22}$

Later in 2016, Kamali et al. ${ }^{26}$ conducted series of $\mathrm{CO}_{2}$ WAG and Simultaneous Water-and-Gas (SWAG) injections using similar rock and fluid system as their previous work. The pressure and temperature were the same as abovementioned. Table 10 summarizes the ultimate oil recovery for continuous gas injection, WAG and SWAG with fraction gas injected of 0.5. Their results showed that miscible $\mathrm{CO}_{2}$ WAG injection gives the best performance and miscible and immiscible WAG and SWAG outperformed continuous gas injection. Generally, it was observed that as miscibility increases (IFT decreases) the recovery also increases.

Table 10 Recovery factors for miscible, near-miscible and immiscible $\mathrm{CO}_{2}$ CGI,WAG and SWAG injections ${ }^{26}$

\begin{tabular}{llll}
\hline Experiment & $\begin{array}{l}\text { Injected } \\
\text { PV }\end{array}$ & IFT, $\mathbf{m N} / \mathbf{m}$ & $\begin{array}{l}\text { Recovery, } \\
\text { fraction of OIP }\end{array}$ \\
\hline CGI & 2.8 & 0.0 (miscible) & 0.73 \\
CGI & 2.8 & 0.06 (near-miscible) & 0.73 \\
CGI & 1.6 & 2.7 (immiscible) & 0.52 \\
WAG & 4.8 & 0.0 (miscible) & 0.8 \\
WAG & 4.8 & 0.06 (near-miscible) & 0.73
\end{tabular}

(Table 10 continue...)

$\begin{array}{llll}\text { WAG } & 4.8 & 2.7 \text { (immiscible) } & 0.67 \\ \text { SWAG } & 4.8 & 0.0 \text { (miscible) } & 0.68 \\ \text { SWAG } & 4.8 & 0.06 \text { (near-miscible) } & 0.68 \\ \text { SWAG } & 4.8 & 2.7 \text { (immiscible) } & 0.64\end{array}$

\section{Conclusion}

In this study, the effect of gas/oil IFT reduction on three-phase relative permeabilities has been reviewed. Furthermore, the performance of WAG injections at immiscible (high gas/oil IFT) and near-miscible (very low gas/oil IFT) conditions in laboratory scale was compared. The following conclusions can be drawn from this study:

- The gas/oil IFT reduction affects the relative permeability of all three phases. As the gas/oil IFT decreases, kro and krg increase but the behavior of $\mathrm{k}_{\mathrm{rw}}$ is uncertain. The observed effect on the $\mathrm{k}_{\mathrm{rw}}$ should be further investigated.

- In the most of research studies on immiscible WAG injection, presented in this paper, the major reduction in oil saturation is achieved in the first cycle. The only exception is for near-miscible WAG injection where the oil saturation keeps decreasing to the last injection cycle.

- The miscible WAG injection outperformed other injection scenarios.

- Although there is not enough literature data on the performance of near-miscible WAG injection, but based on the data presented, the performance of near-miscible WAG is generally better than that of immiscible WAG.

- The immiscible WAG experiments that started with gas injection (WAG-DI) have higher oil recovery than those starting with water flooding (WAG-ID) for both water-wet and mixed-wet systems.

\section{Acknowledgement}

This work was carried as part of the "Improved Characterization of Three-Phase Flow and Water- Alternating-Gas (WAG) Injection" joint industry project (JIP) at the "Centre for Enhanced Oil Recovery and $\mathrm{CO}_{2}$ Solutions" of the Heriot-Watt University. The project is currently supported equally by: ADCO, BG-Shell, Galp Energia, Maersk, Petrobras, Premier Oil, Schlumberger, Total E\&P, and Woodside, which is gratefully acknowledged.

\section{Nomenclature}

$k_{r g}$ : gas relative permeability

$k_{r o}:$ oil relative permeability

$k_{r w}:$ water relative permeability

$S_{o i}$ initial oil saturation

$S_{w i}:$ initial water saturation

$S_{\text {wir }}$ : irreducible water saturation

$S_{o r}$ G1: remaining oil saturation after secondary gas injection 


\section{$S_{o r} W 1$ : remaining oil saturation after secondary water flooding}

$S_{o r} G 2,3,4$ : remaining oil saturation after tertiary gas injection, 2 for second cycle, 3 for third cycle and 4 for forth cycle

$S_{o r} W 2,3,4$ : remaining oil saturation after tertiary water flooding, 2 for second cycle, 3 for third cycle and 4 for forth cycle

\section{$S_{o r} W A G$ : remaining oil saturation at the end of WAG injection}

\section{IFT: Interfacial Tension}

$W A G-D I$ : Secondary gas injection followed by alternating water and gas injections (gas-water-gas-water...)

$W A G-I D$ : Secondary water flooding followed by alternating gas and water injections (water-gas-water-gas...)

$C G I$ : Continuous Gas Injection

$T R F$ : Tertiary Recovery Factor

OIP: Oil in place

$P V:$ Pore volume

$m D$ : milliDarcy

\section{References}

1. Bardon C, Longeron DG. Influence of Very Low Interfacial Tensions on Relative Permeability 1 . Longeron DG. Influence of very low interfacial tensions on relative permeability. SPE Journal. 1980;20(5):391-401.

2. Asar H, Handy LL. Influence of interfacial tension on gas/oil relative permeability in a gas-condensate system. SPE Reservoir Engineering. 1988;3(1):257-264.

3. McDougall SR, Salino PA, Sorbie KS. The effect of interfacial tension upon gas-oil relative permeability measurements: interpretation using pore-scale models. In: SPE Annual Technical Conference and Exhibition. Society of Petroleum Engineers. 1997.

4. Henderson GD, Danesh A, Tehrani DH, et al. The effect of velocity and interfacial tension on relative permeability of gas condensate fluids in the wellbore region. J Pet Sci Eng. 1997;17(3-4):265-273.

5. Henderson GD, Danesh A, Tehrani DH, et al. Measurement and Correlation of Gas Condensate Relative Permeability by the Steady-State Method. SPE Reservoir Evaluation \& Engineering. 1998;1(2):134-140.

6. Blom SMP, Hagoort J, Soetekouw DPN. Relative Permeability at NearCritical Conditions. SPE Journal. 2000;5(2):172-181.

7. Al-Wahaibi YM, Grattoni CA, Muggeridge AH. Drainage and imbibition relative permeabilities at near miscible conditions. J Pet Sci Eng. 2006;53(3-4):239-253.

8. Jahanbakhsh A, Shahverdi H, Sohrabi M. Relative Permeability Normalization-Effects of Permeability, Wettability and Interfacial Tension. In: SPE Annual Technical Conference and Exhibition. Society of Petroleum Engineers. 2014.

9. Delshad M, Delshad M, Pope GA, et al. Two- and Three-Phase Relative Permeabilities of Micellar Fluids. SPE Formation Evaluation. 1987;2(3):327-337.

10. Dria DE, Pope GA, Sepehrnoori K. Three-phase gas/oil/brine relative permeabilities measured under $\mathrm{CO}_{2}$ flooding conditions. SPE Reservoir Engineering. 1993;8(2):143-150.
11. Cinar Y, Orr FM. Measurement of Three-Phase Relative Permeability with IFT Variation. SPE Reservoir Evaluation \& Engineering. 2005;8(1):33-43.

12. Cinar Y, Marquez S, Orr FM. Effect of IFT variation and wettability on three-phase relative permeability. SPE Reservoir Evaluation \& Engineering. 2007;10(3):211-220.

13. Fatemi SM, Sohrabi M, Ireland S, et al. Recovery Mechanisms and Relative Permeability for Oil/Gas System at Near-miscible Conditions: Effects of Immobile Water Saturation, Wettability, Hysteresis and Permeability. In: SPE Improved Oil Recovery Symposium. Society of Petroleum Engineers. 2012.

14. Fatemi SM, Sohrabi M. Mechanistic Study of the Effect of Gas/Oil IFT on the Performance of Gas, WAG and SWAG Injections in Mixed-Wet Systems. In: SPE Annual Technical Conference and Exhibition. Society of Petroleum Engineers. 2015.

15. Jahanbakhsh A, Sohrabi M, Fatemi SM, et al. A Comparative Study of the Effect of Gas/Oil IFT Variation on Two- and Three-Phase Relative permeability and the Performance of WAG Injection at Laboratory Scale. In: SPE Improved Oil Recovery Symposium. 2016.

16. Skauge A, Sorbie K. Status of fluid flow mechanisms for miscible and immiscible WAG. In: SPE EOR Conference at Oil and Gas West Asia. Society of Petroleum Engineers. 2014.

17. Christensen JR, Stenby EH, Skauge A. Review of WAG field experience. In: International Petroleum Conference and Exhibition of Mexico. Society of Petroleum Engineers. 1998.

18. Rao DN. Gas Injection EOR-A new meaning in the new millennium. Journal of Canadian Petroleum Technology. 2001;40(2):11-18.

19. Skauge A, Larsen JA. Three-phase relative permeabilities and trapped gas measurements related to WAG processes. In: SCA 9421, proceedings of the International Symposium of the Society of Core Analysts, Stavanger, Norway. 1994.

20. Minssieux L. WAG Flow Mechanisms in Presence of Residual Oil. SPE Annual Technical Conference and Exhibition. Society of Petroleum Engineers. 1994.

21. Egermann P, Vizika O, Dallet L, et al. Hysteresis in three-phase flow: experiments, modeling and reservoir simulations. In: SPE European Petroleum Conference. Society of Petroleum Engineers. 2000.

22. Element DJ, Masters JHK, Sargent NC, et al. Assessment of three-phase relative permeability models using laboratory hysteresis data. In: SPE International Improved Oil Recovery Conference in Asia Pacific. Society of Petroleum Engineers. 2003.

23. Kulkarni MM, Rao DN. Experimental investigation of miscible and immiscible Water-Alternating-Gas (WAG) process performance. J Pet Sci Eng. 2005;48(1-2):1-20.

24. Sohrabi M, Tehrani DH, Al-Abri M. Performance of near-miscible gas and swag injection in a mixed-wet core. In: International Symposium of the Society of Core Analysts. 2007.

25. Kamali F, Hussain F, Cinar Y. A Laboratory and Numerical-Simulation Study of Co-Optimizing $\mathrm{CO}_{2}$ Storage and $\mathrm{CO}_{2}$ Enhanced Oil Recovery. SPE Journal. 2015;20(6):1227-1237.

26. Kamali F, Hussain F, Cinar Y. An experimental and numerical analysis of water-alternating-gas and simultaneous-water-and-gas displacements for carbon dioxide enhanced oil recovery and storage. SPE Journal. 2017;22(2):521-538. 